\title{
CHLORIDE RESISTANCE OF BLENDED ASH GEOPOLYMER CONCRETE
}

\author{
Mohd Azreen Mohd Ariffin ${ }^{1,3}$, Mohd Warid Hussin ${ }^{2}$, \\ ${ }^{1}$ Faculty of Civil Engineering, Universiti Teknologi Malaysia, Malaysia \\ ${ }^{2}$ Institute for Smart Infrastructure and Innovative Construction (ISIIC), Faculty of Civil Engineering, Universiti Teknologi \\ Malaysia, Malaysia \\ ${ }^{3}$ Forensic Engineering Centre, Faculty of Civil Engineering, Universiti Teknologi Malaysia, Malaysia
}

Date received: 16/08/2015, Date accepted: 25/08/2015

Corresponding author's email: mohdazreen@utm.my

\begin{abstract}
Chloride attack on concrete is a mechanism of deterioration which causes corrosion of steel reinforcement. Geopolymer, an alternative aluminosilicate binder material, has attracted attention for its structural and durability performance as well as for environmental benefits in reducing the $\mathrm{CO}_{2}$ emissions associated with concrete production. However, the understanding of its behaviour in the chloride resistance of geopolymer concrete especially from mixtures of pulverized fuel ash (PFA) and palm oil fuel ash (POFA) is scarce. In this study, geopolymer concrete using blended ashes from agro-industrial waste were tested for chloride content using ASTM 1543-10a (Standard Test Method for Determining the Penetration of Chloride Ion into Concrete). The geopolymer concrete samples were prepared using a mix of the PFA and POFA as the main binder components at the range of alkaline/binder ratio of 0.4 together mixed with coarse and fine aggregates. The ambient temperature $\left(26-30^{\circ} \mathrm{C}\right)$ of curing regimes was used. The specimens were cast in $100 \mathrm{~mm} 3 \mathrm{molds}$. After achieving the targeted compressive strength $(25-30 \mathrm{MPa})$, the specimens were immersed for 18 months to $2.5 \%$ solution of sodium chloride $(\mathrm{NaCl})$. The normal OPC concrete with similar compressive strength were also prepared for direct comparison. X-ray diffraction (XRD), Fourier Transformed Infrared Spectrometer (FTIR), Thermogravimetry analyser (TGA-DTG) and Field Emission Scanning electron microscopy images with energy dispersive X-ray (FESEM-EDX) were performed to analyze the microstructural characterisation of the materials. In particular, geopolymer concrete had shown a better resistance to chloride penetration as compared to OPC concrete
\end{abstract}

Keywords: Geopolymer, Palm Oil Fuel Ash (POFA), Chloride, Durability

\subsection{INTRODUCTION}

$\mathrm{W}$ ITH an annual production of almost $3 \mathrm{Gt}$, Ordinary Portland cement (OPC) is the dominant binder of the construction industry [1-2]. The production of one ton of OPC generates almost one tone of $\mathrm{CO}_{2}$. Manufacturing of cement accounts for as much as $5 \%$ of global $\mathrm{CO}_{2}$ emissions to the environment, making one of the main contributors to global climate change [3]. Research works carried out so far in the development of alkali-activated cements showed that much has already been investigated and also that an environmental friendly alternative to Portland cement is rising [4]. Davidovits [5] was one of the author to address the carbon dioxide emissions of these binders stating that they generate just 0.184 tons of $\mathrm{CO}_{2}$ per ton of binder. Geopolymer is a potentially valuable new material for use in the concrete and construction industry. Made from industrial by products or wastes from processes such as pulverized fuel ash (PFA), and iron manufacture (slag), these low- $\mathrm{CO}_{2}$ binders have proven to give comparable mechanical properties to normal Portland cement concrete, and ongoing work, including the study presented in this paper, is giving increased confidence in its likely durability in service. Geopolymer is synthesized from a combination of an alkaline solution with a reactive aluminosilicate powder such as metakaolin, fly ash and/or slag. The reaction of the aluminosilicate with the alkali results in the dissolution of the solid raw material, forming a disordered alkali aluminosilicate gel phase known as the geopolymeric gel binder, which also contains some embedded partially reacted solid precursor particles, and the water used in mixing [6].

The development of understanding of aggressive environments attacks on concrete is probably the most extensively observed and researched aspect of concrete durability worldwide. Chloride attack is one of an important durability and serviceability concern for geopolymer materials used in construction. Corrosion of embedded steel bars is the main consequence when chloride penetrates into concrete. The 
applications of de-icing salts, marine exposure, airborne salt or sodium chloride are the sources of chloride ions that can pose threats to concrete structures. Steel embedded in concrete usually has a protective passive layer, which is formed as an oxide layer while the $\mathrm{pH}$ of the pore solution is sufficiently high. However, when chloride ions are present, the protective layer will be destroyed, leading to corrosion of the steel reinforcement. Furthermore, different types of chlorides such as $\mathrm{NaCl}$ and $\mathrm{CaCl}_{2}$ would also cause the changes of microstructure of concrete [7]. To date, there have been limited investigations on the effects of chloride ingress in geopolymer concrete. This paper generally focuses on the use XRD, FTIR, FESEM-EDX and TGA-DTG techniques for investigating blended ash geopolymer (BAG) concrete using PFA and POFA from agro-industrial wastes. The durability of BAG concrete in comparison with OPC concrete immersed in sodium chloride with $2.5 \%$ concentration up to 18 months was investigated.

\subsection{METHODOLOGY}

In the present experimental work, dry pulverized fuel ash (PFA) obtained from the silos of Kapar Power Station, Selangor, Malaysia was used. While, Palm Oil Fuel Ash (POFA) was obtained as a result of burning of palm oil shell and husk from Kahang mill in Johor, Malaysia. The PFA and POFA have a mean particle size of $45 \mu \mathrm{m}$. The main chemical compositions of the PFA, POFA and ordinary Portland cement (OPC) as determined by X-Ray Fluorescence are shown in Table 1. The silica/alumina ratio $\left(\mathrm{SiO}_{2} / \mathrm{Al}_{2} \mathrm{O}_{3}\right)$ is approximately 1.3 for PFA whereas POFA has higher silica content and reactive silica. To activate the blended ash, a commercial grade sodium hydroxide $(\mathrm{NaOH})$ and sodium silicate $\left(\mathrm{Na}_{2} \mathrm{SiO}_{3}\right)$ solutions were used as alkaline activator. Local crushed granite sand with a specific gravity of 2.62 and aggregates (10mm sizes) were used for making concrete. In order to improve the workability, high range water reducing super plasticizer (naphthalene sulphonate) and extra water was added to the mixture.

Table1. Chemical Composition (\%) of PFA, POFA and OPC

\begin{tabular}{ccccccccc}
\hline Type & $\mathrm{SiO}_{2}$ & $\mathrm{Al}_{2} \mathrm{O}_{3}$ & $\mathrm{Fe}_{2} \mathrm{O}_{3}$ & $\mathrm{CaO}$ & $\mathrm{MgO}$ & $\mathrm{Na}_{2} \mathrm{O}$ & $\mathrm{K}_{2} \mathrm{O}$ & LOI \\
\hline PFA & 46.7 & 35.9 & 5.0 & 3.9 & 0.8 & 0.6 & 0.5 & 1.0 \\
POFA & 53.5 & 1.9 & 1.1 & 8.3 & 4.1 & 1.3 & 6.5 & 18.0 \\
OPC & 29.1 & 5.0 & 2.6 & 59.0 & 1.1 & 0.2 & 0.5 & 1.3 \\
\hline
\end{tabular}

Geopolymer concrete can be manufactured by adopting the conventional techniques used in the manufacture of OPC concrete. In the laboratory work, the blended ash and the aggregates were first dry mixed in 80 litre capacity pan mixer for five minutes. Both coarse and fine aggregates were in saturated surface dry condition. The alkaline liquid containing sodium hydroxide and sodium silicate was added and mixed for another five minutes. All geopolymer concrete specimens were prepared with an alkaline solution to blended ash ratio of 0.4 by mass and the concentration of $\mathrm{NaOH}$ in solution was 14Molar. The ratio of sodium silicate $\left(\mathrm{Na}_{2} \mathrm{SiO}_{3}\right)$ to sodium hydroxide $(\mathrm{NaOH})$ was 2.5 by mass. The super plasticizer was used to achieve the workability of geopolymer concrete in between $80-100 \mathrm{~mm}$ slump. Some additional water was also added to the mixture.

A class F PFA and POFA have been activated in an alkaline solution to form Geopolymer gel and further binding aggregates to make concrete. The preparation process and composition of the investigated materials were developed and published earlier [8].

The salt ponding test is one of the tests that are commonly used around the world in identifying the chloride penetration into a concrete. Modified to ASTM C1543-10a (Standard Test Method for Determining the Penetration of Chloride Ion into Concrete by Ponding), this process is done by exposing the top surface of samples $100 \mathrm{~mm}$ concrete cubes to a solution containing chloride where sodium chloride $(\mathrm{NaCl})$ is used. The solution is ponded, at least $20 \mathrm{~mm}$ high as to create enough amount of chloride to penetrate the sample and the process is set to at least 18 months so that a significant result can be achieved. 
Immediately after completing the immersion period, the samples are then dried of the solution and left to dry for one day, where deposits of white salts can be found on the surface of the sample, brush off the salts before further tests can be done. In Figure 1, the samples are sliced at a depth of 10-20mm (Disc1), 25-35mm (Disc2), 40-50mm (Disc3) and 55-65mm (Disc 4).

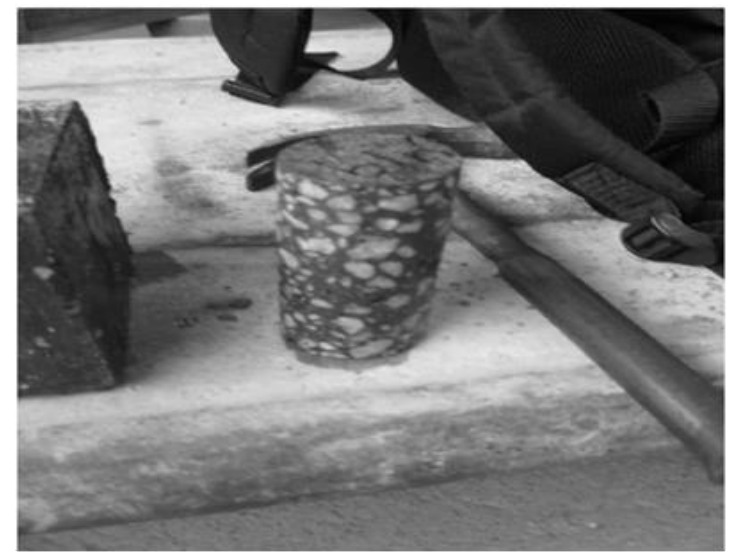

Figure 1 Depth of sample

The samples were then ground to powder forms in order to determine the chloride ion content. The tests are carried out by using the chloride penetration machine (HACH Machine). Control specimens (without salt ponded test) are kept in ambient condition for comparison.

OPC concrete with water/binder $(\mathrm{w} / \mathrm{b})$ ratio 0.6 was used. The specimens with $\mathrm{w} / \mathrm{b}=0.6$ had the same consistency as the geopolymer specimens at $\mathrm{w} / \mathrm{b}=0.4$. Thus, the specimens were compared as having the same consistency at the time of testing. The compressive strength of OPC and BAG concrete at the age of 28days were $27 \mathrm{MPa}$ and 28MPa respectively.

$2.5 \%$ concentration of the sodium chloride solution $(\mathrm{NaCl})$ is used as the permeating reagent. All surfaces of the specimens are coated with a sealant except one. The test was done for 18 months where the sample was left to be submerged in the solution for the whole duration in order to permeate the sample through the uncoated surface; this will give the ideas on how much chloride can penetrate through the specimens. OPC concrete was also prepared as a comparison. In order to obtain the result of chloride content from the solid specimens in powder form of the discs, it needed to be changed into the liquid form by a dilution process with distilled water as shown in Figure 2.

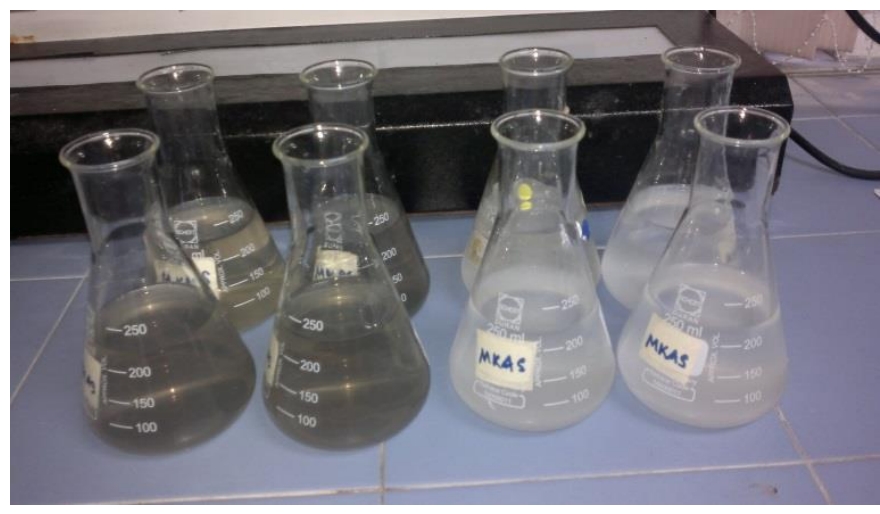

Figure 2. Samples in liquid form

Equation (1) was based on American Public Health Association Standard Methods (APHA) shows the conversion of of chloride content, mg/L obtained from HACH Machine DR5000 into percentage (\%) of the chloride for each of the specimen tested: 
Where,

$\mathrm{C}=$ chloride concentration as read directly from instrument or

Total $(\mathrm{mg} / \mathrm{L})=$ Test - Control $(\mathrm{mg} / \mathrm{L})$.

$\mathrm{F}_{1}=$ Dilution Factor1 or weight of sample ash, $2 \mathrm{~g}$ dilute into

$250 \mathrm{ml}$ of distilled water

$=250 / 2$

$=125$

$\mathrm{F}_{2}=$ Dilution Factor 2 or $10 \mathrm{ml}$ of sample in liquid dilute into

$240 \mathrm{ml}$ of distilled water

$=250 / 10$

$=25$

$\mathrm{ppm}=(1 / 10000) \%, 1 \%=100000 \mathrm{mg} / \mathrm{L}(\mathrm{ppm})$

\subsection{RESULTS AND ANALYSIS}

\subsection{Chloride analysis}

Table 2 shows the chloride content for both OPC and BAG concrete. The first layer (Disc 1) of the sample gives a higher chloride penetration. This resulted due to the disc being exposed more of the solution than others after 18 months chloride ingress by the absorption process.

Table 2. Chloride Content (\%) of BAG and OPC concrete after 18month immersion

\begin{tabular}{|c|c|c|c|c|c|}
\hline \multirow[b]{2}{*}{ Samples } & \multirow[b]{2}{*}{ Disc } & \multicolumn{3}{|c|}{$\begin{array}{l}\text { Chloride concentration } \\
\text { (mg/L) }\end{array}$} & \multirow{2}{*}{$\begin{array}{l}\text { Chloride } \\
\text { Content (\%) }\end{array}$} \\
\hline & & Test & Control & Total & \\
\hline \multirow{4}{*}{ BAG } & 1 & 0.70 & 0.05 & 0.65 & 0.20 \\
\hline & 2 & 0.50 & 0.02 & 0.48 & 0.15 \\
\hline & 3 & 0.40 & 0.01 & 0.39 & 0.12 \\
\hline & 4 & 0.30 & 0.00 & 0.30 & 0.09 \\
\hline \multirow{4}{*}{ OPC } & 1 & 1.00 & 0.20 & 0.80 & 0.25 \\
\hline & 2 & 0.80 & 0.15 & 0.65 & 0.20 \\
\hline & 3 & 0.60 & 0.12 & 0.48 & 0.15 \\
\hline & 4 & 0.50 & 0.08 & 0.42 & 0.13 \\
\hline
\end{tabular}

From Figure 3, BAG concrete shows a lower amount of chloride content compared to OPC concrete samples. The ingress of chloride is significantly less in samples that are made of geopolymer compared to OPC. At the critical point, Disc 1 (10-20mm depth) shows that for BAG concrete, it does not exceed $0.20 \%$ while in OPC give the highest value up to $0.25 \%$. At the lowest point, Disc 4 (55-65mm depth), samples of OPC give the highest content of chloride that is $0.13 \%$ while BAG concrete gives the value of $0.09 \%$. This result shows that the durability of the BAG concrete is significantly higher compared to OPC concrete in term of chloride penetration. 


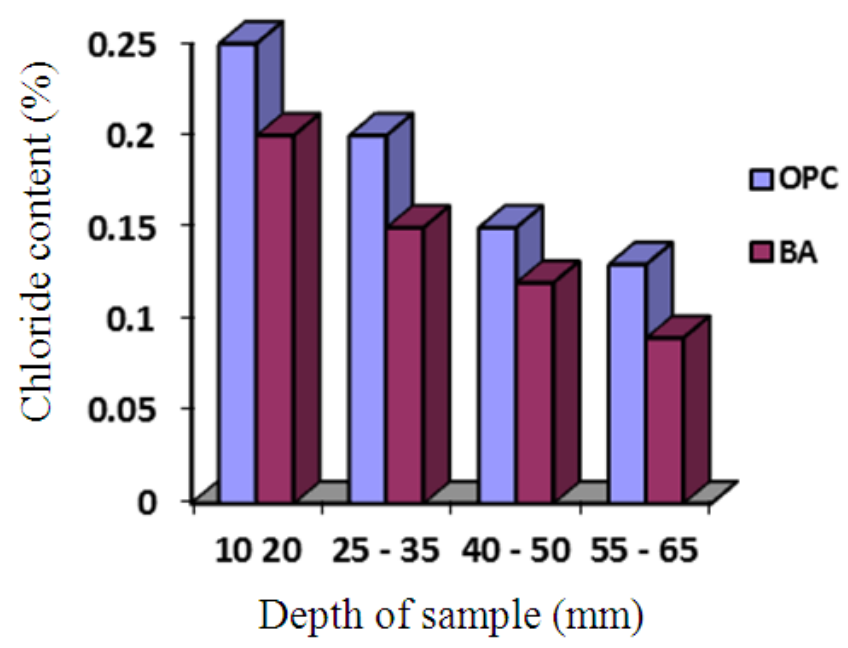

Figure 3. Chloride content (\%) at different depth

The BAG concrete showed better performance than the OPC concrete when immersed in $\mathrm{NaCl}$ with $2.5 \%$ concentration due to difference in chemical composition. The chemistry of the material was certainly very important for its durability. The chloride penetration of OPC is higher due to the chemical composition with high calcium content whereas the BAG specimens with low Ca content performed significantly better than OPC specimens.

\subsection{X-ray diffraction (XRD) analysis}

X-ray diffraction (XRD) technique was used to obtain a better understanding of the possible transformation in the original materials as well as the samples immersed in $\mathrm{NaCl}$. The reaction between PFA, POFA and the alkaline activator i.e. sodium silicate and sodium hydroxide resulted in a partial crystalline phase. The broad peaks of the geopolymer component can be seen in the region $25-30^{\circ} \mathrm{C} 2 \theta$. Mineralogical characterization of the reaction product of alkali activation of the BAG concrete in Figure 4, shows crystalline quartz $(\mathrm{Q})$, albite $(\mathrm{A})$ and gmelinite $(\mathrm{Gm})$. The main phase of BAG concrete discovered was a crystalline N-A-S-H phase, similar to albite ( $\mathrm{NaAlSi}_{3} \mathrm{O}$, PDF03-0451) [9-12]. Another phase in BAG concrete was gmelinite which produced from the reaction product of geopolymerisation and its represent the nanostructure of the zeolite precursor [13-15]. Figure 4, shows the XRD analysis results for the BAG concrete which consists of the samples (Disc1-4) after immersion in $\mathrm{NaCl}$. In the initial sample, a semi-crystalline aluminosilicates gel (N-A-S-H) is detected as a main phase and it is still observed after immersing in $\mathrm{NaCl}$. 


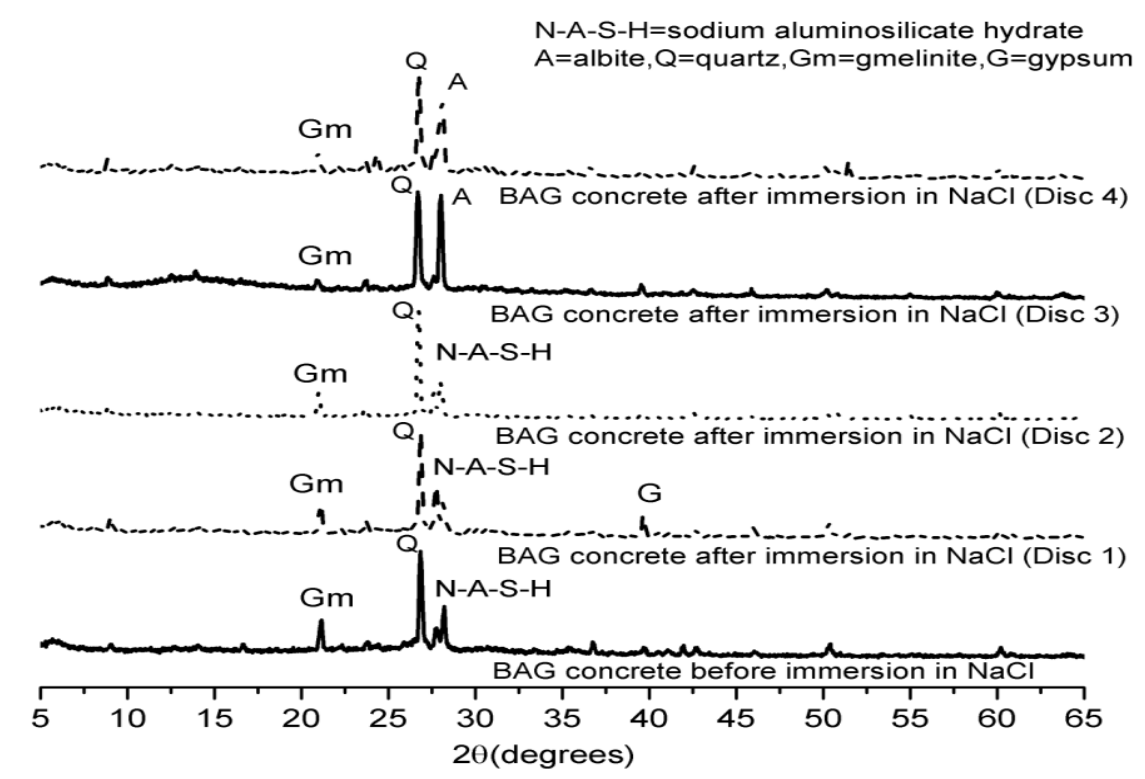

Figure 4. XRD for BAG concrete after 18 months immersion in $\mathrm{NaCl}$

Conversely, the OPC concrete shows a different picture when immersing in $\mathrm{NaCl}$. Chloride penetration in concrete based on Portland cement is generally attributed to the formation of Friedel's salt, and ettringite, with the presence of chloride ion and/or sulphate ion [16-18]. Figure 5, presents the XRD for the OPC concrete before and after immersion of $\mathrm{NaCl}$. The OPC concrete, shows strong intensity peaks for quartz and C-S-H phase which similar to anorthite $\left(\mathrm{CaAl}_{2} \mathrm{Si}_{2} \mathrm{O}_{8}, \mathrm{PDF} 10-0379\right)$ [8]. When the OPC concrete immersed in $\mathrm{NaCl}$ (Disc1-3), the chloride ions intrude into concrete and react with portlandite $\mathrm{Ca}(\mathrm{OH})_{2}$ to generate calcite. The absence of portlandite is described by its chemical reaction in the presence of $\mathrm{CO}_{2}$ to form calcium carbonate (calcite)[17-18]. Contrary to the samples of the depth interval (Disc1-3), the XRD for the Disc 4 shows the peaks for Portlandite phase and ettringite. However, the peak for calcite is not appearing which suggests the absence of severe carbonation at particular depths (Disc4). The absence of $\mathrm{CaCO}_{3}$ is connected by the presence of portlandite. Sulphate ions may penetrate into concrete from an external environment, its can react with $\mathrm{C}_{3} \mathrm{~A}$ during its hydration process to form monosulphoaluminate or ettringite.

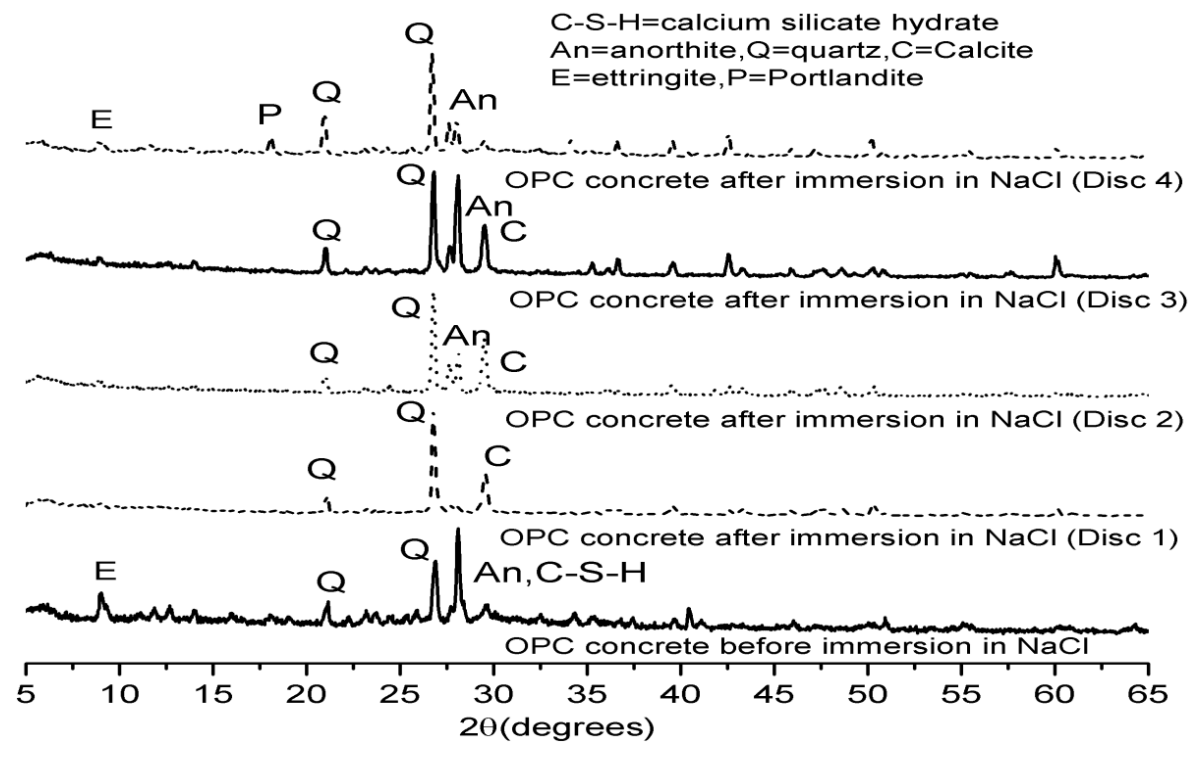

Figure 5. XRD for OPC concrete after 18 months immersion in $\mathrm{NaCl}$ 


\subsection{Fourier Transform Infra Red (FTIR) Spectroscopy analysis}

The FTIR spectra in Figure 6\&7, indicates major bands at approximately 3470, 1650, 1425, 1030 and $780 \mathrm{~cm}^{-1}$ in BAG concrete and 3455, 1655, 1440, $995 \mathrm{~cm}^{-1}$ in OPC concrete before immersion in NaCl. The structure of molecular from 3200 to $3700 \mathrm{~cm}^{-1}$ is characterized by the $\mathrm{O}-\mathrm{H}$ stretching band water system, while the bending of the chemically bonded $\mathrm{H}-\mathrm{O}-\mathrm{H}$ is located at $1650 \mathrm{~cm}^{-1}$ which related to water bound in the hydrated products formed after alkaline activation [20]. Thus, the bands at 995 to $1035 \mathrm{~cm}^{-1}$ are assigned to quartz as the crystalline phase in the both samples. The carbonate in the system is characterized by absorption at 1425 to $1440 \mathrm{~cm}^{-1}$, which is consistent with the presence of anorthite and calcite particularly in OPC concrete. The main binder gel band appears at $995 \mathrm{~cm}^{-1}$, assigned to the asymmetric stretching mode of the $\mathrm{C}-\mathrm{S}-\mathrm{H}$ structure formed in OPC samples whereas the position at $1030 \mathrm{~cm}^{-1}$ is consistent with $\mathrm{N}-\mathrm{A}-\mathrm{S}-\mathrm{H}$ gels formed in geopolymer binder systems derived from solid precursor used [21-22]. Figure 6 shows the FTIR spectra of the BAG concrete samples before and after immersing in $\mathrm{NaCl}$ shows minor differences only at the depth interval (Disc 1) due to the presence of gypsum as identified in XRD diagrams. The bands at approximately $3470 \mathrm{~cm}^{-1}$ and 1650 $\mathrm{cm}^{-1}$ are attributed to $\mathrm{O}-\mathrm{H}$ stretching and $\mathrm{O}-\mathrm{H}$ bending, respectively, being characteristic of weakly bound molecules of water [23]. On the other hand, presence of albite as identified by XRD give the NA-S-H binder gel of BAG concrete, still maintained at their position after immersion. It indicates that, most of the molecular chains consisting of $\mathrm{SiO}_{4}$ and $\mathrm{AlO}_{4}$ tetrahedra linked alternately by sharing all the oxygens, are not significantly destroyed by $\mathrm{NaCl}$ solution.

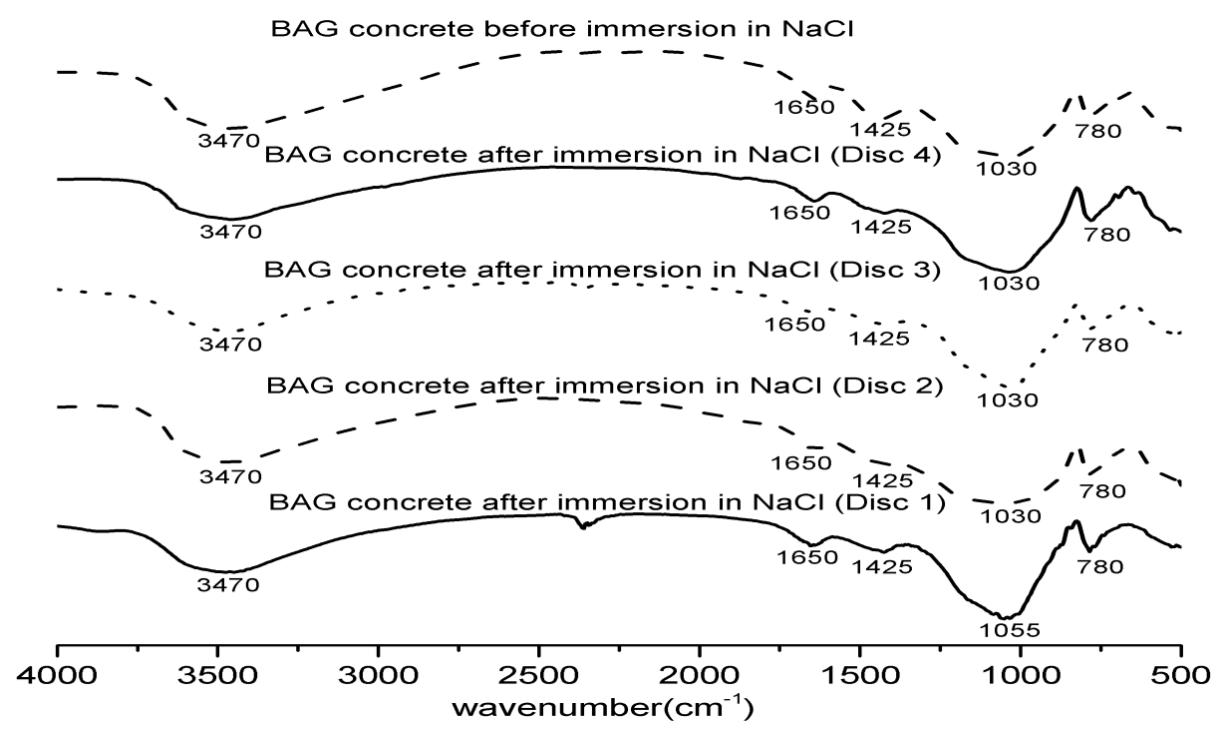

Figure 6. FTIR for BAG concrete after 18 months immersion in $\mathrm{NaCl}$

Conversely, the reaction of the OPC samples after immersion shows the marked decomposition of the $\mathrm{C}-\mathrm{S}-\mathrm{H}$ phase in the microstructure, and Figure 6 shows distinct differences between before and after immersion. The chemically bonded carbonate at $1440 \mathrm{~cm}^{-1}$ has changed to $1425 \mathrm{~cm}^{-1}$ which are contributed by the presence of anorthite and calcite as identified by XRD. Finally, the decomposition of the main binder, C-S-H gel is associated with the shifting from $995 \mathrm{~cm}^{-1}$ of the new bands at 1095,955 $\mathrm{cm}^{-1}$ for Disc $4,1025 \mathrm{~cm}^{-1}$ for Disc $2 \& 3$ and $1040 \mathrm{~cm}^{-1}$ for Disc 1 after immersion in $\mathrm{NaCl}$. It is also consistent with the degradation of the binder which assigned to the presence of anorthite and calcite. It's shown that the OPC concrete were altered by the $\mathrm{NaCl}$ immersion. 


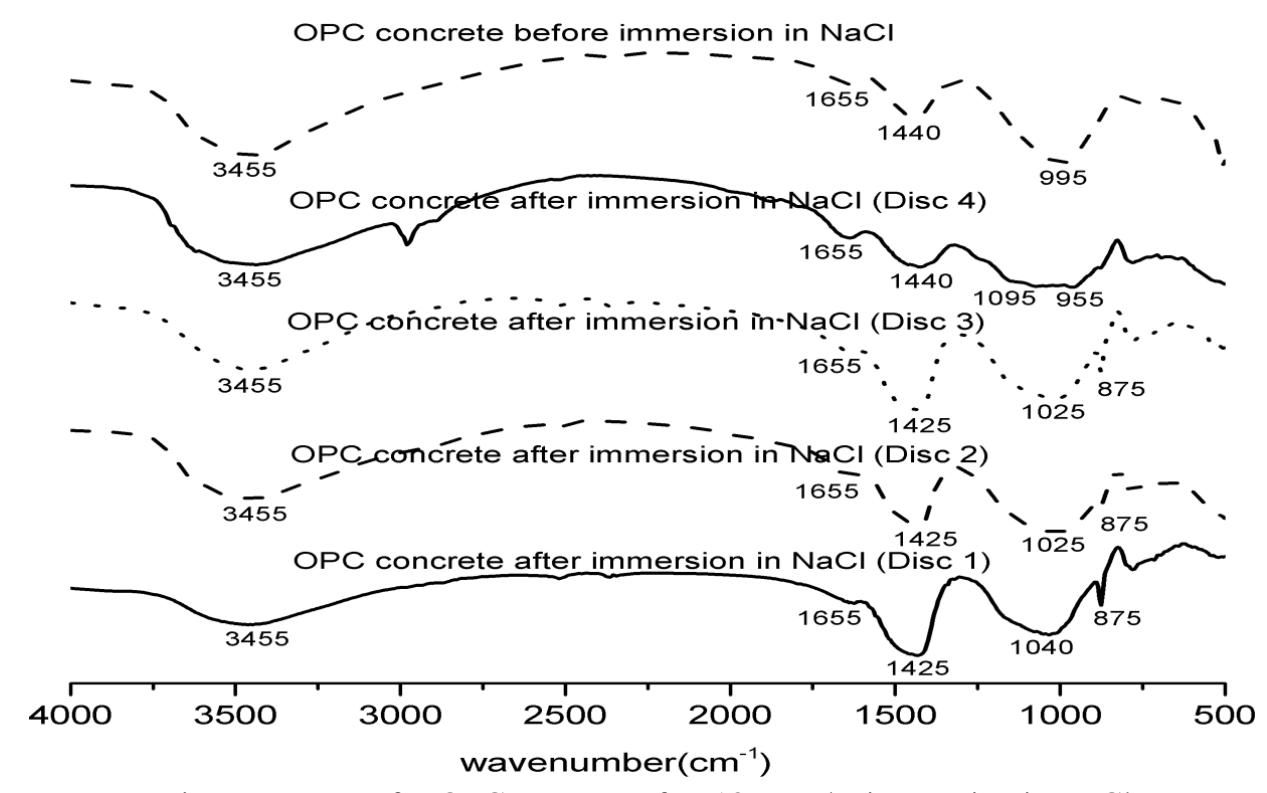

Figure 7. FTIR for OPC concrete after 18 months immersion in $\mathrm{NaCl}$

\subsection{Thermogravimetry (TGA/DTG) analysis}

The results of the thermal analysis support the above argument as shown in Figure $8 \& 9$ (TGA-DTG). Both samples were crushed and sieved then analyzed using derivative thermogravimetry (TGA-DTG). The mass loss (TGA) occurs for both samples at the depth interval from Disc 1-4 as shown in Figure 8 (a). The Figure shows the 23\% mass loss (Disc 1) is observed compared to 28\% (Disc 2), 17\% (Disc 3) and $15 \%$ (Disc 4) when BAG concrete immersed in $\mathrm{NaCl}$ for about 18 months. DTG data in Figure 9 (a) represent the characteristics of samples based on TGA at the specified range of temperature. Gypsum has been characterized at depth interval (Disc 1), at the peak centered of $705^{\circ} \mathrm{C}$ temperature range, probably resulting from reactions involving atmospheric $\mathrm{CO}_{2}$ as identified in the XRD diagram. On the other hand, there is no other Gypsum appeared in the Disc 2-4 of the samples. In addition, no ettringite was detected in BAG concrete at all depth intervals (Disc 1-4), consistent with the $\mathrm{Ca} / \mathrm{Si}$ ratio of these systems. The Al was assumed to participate in the formation of $\mathrm{N}-\mathrm{A}-\mathrm{S}-\mathrm{H}$ type gels and thus less available for ettringite formation than Portland cement [9-10]. Conversely, the OPC concrete has higher mass loss as shown in Figure 8(b). The Figure shows, the 38\% mass loss (Disc 1) is identified compared to 33\% (Disc 2), 36\% (Disc 3) and 12\% (Disc 4) after immersing in NaCl. The DTG in Figure 9 (b), shows particularly for the depth interval Disc (1-3), does not exhibit the presence of Friedel's salt and portlandite at the temperature range. On the other hand, a wide endothermic peak centred at $690^{\circ} \mathrm{C}$ confirms the presence of calcite for the depth interval, Disc 1 to Disc 3. Alternatively, the DTG for the Disc 4 depth interval shows a peak of the ettringite and portlandite at centered $140^{\circ} \mathrm{C}$ and $470^{\circ} \mathrm{C}$ respectively. It is common that the presence of sulphate ion from an external environment can react with $\mathrm{C}_{3} \mathrm{~A}$ and its hydration products to form monosulphoaluminate or ettringite. Previous researchers found that the increased of sulphate ion concentrations resulted in slightly decreased chloride binding and the distributions of bound sulphates and chlorides in concrete is subjected to mixed $\mathrm{NaCl}, \mathrm{MgSO}_{4}$ and $\mathrm{Na}_{2} \mathrm{SO}_{4}$ attack $\left.[16,18]\right]$. Thus, the DTG results confirm all the XRD findings for all the depth intervals (Disc 1-4). 

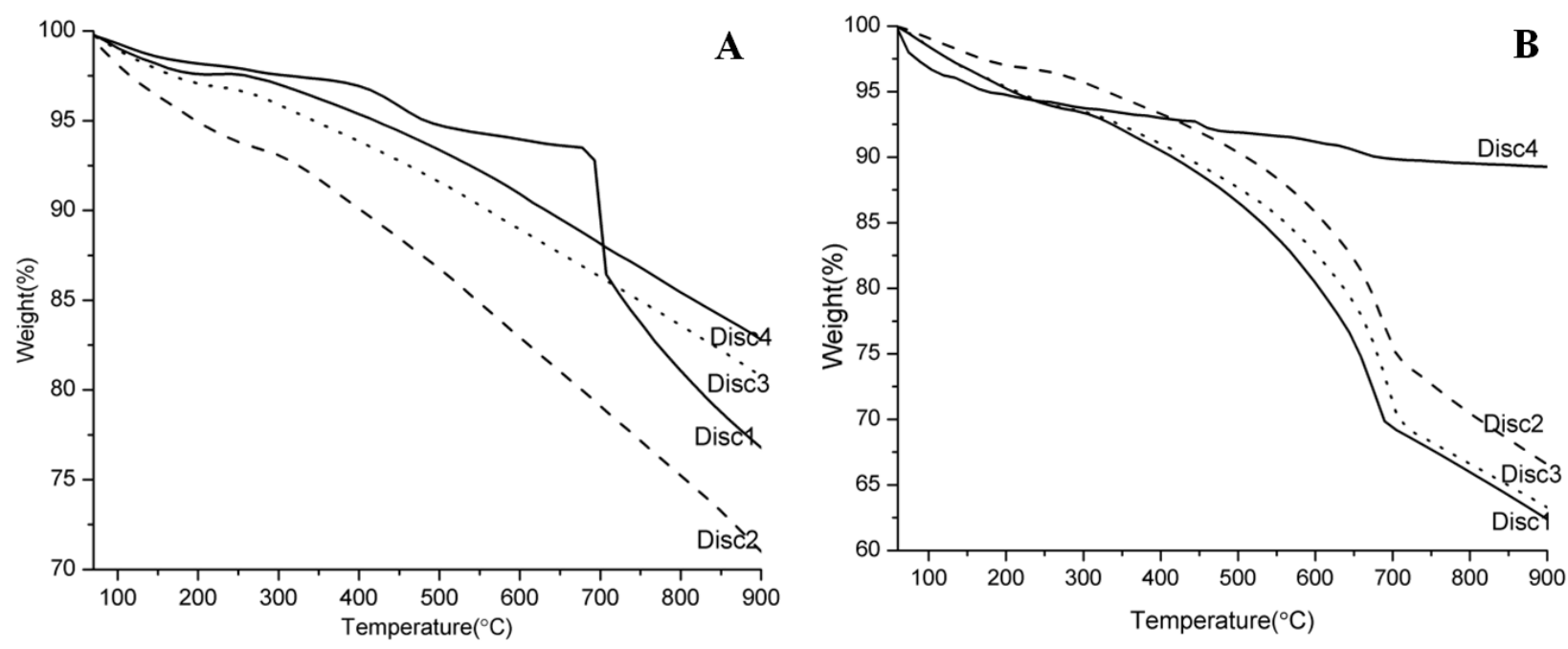

Figure 8. Mass loss for (A) BAG and (B) OPC concrete after 1.5 year immersion in $\mathrm{NaCl}$

B

A
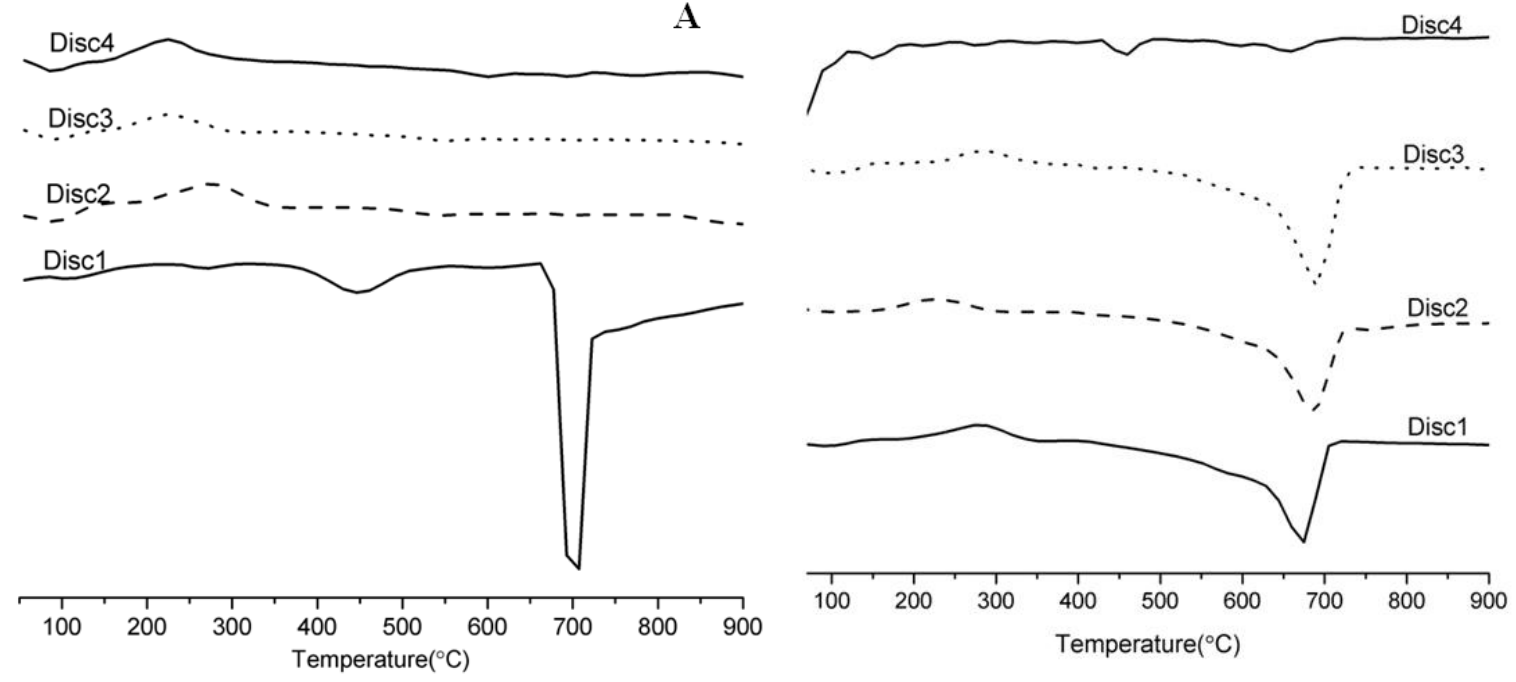

Figure 9. DTG for (A) BAG and (B) OPC concrete after 1.5 year immersion in $\mathrm{NaCl}$

The FESEM and EDX spectrum of concrete specimens at the 55-65mm (Disc4) depth interval after 18 months of immersion in $2.5 \%$ sodium chloride solution are shown in Figure 10. The EDX spectrum of Figure 10 (A) showed a composition of $\mathrm{Ca}-\mathrm{S}$ as indicated by the large presences of $\mathrm{Ca}$ and $\mathrm{S}$. The formation of ettringite is clearly shown [24]. In addition, the OPC specimens became more cracks than BAG, after 18 months immersed in $\mathrm{NaCl}$ solution. Conversely, there is no formation of ettringite for BAG specimens in connection with the absence or less presence of sulphate ion in the concrete, as shown in Figure $10(\mathrm{~B})$. 

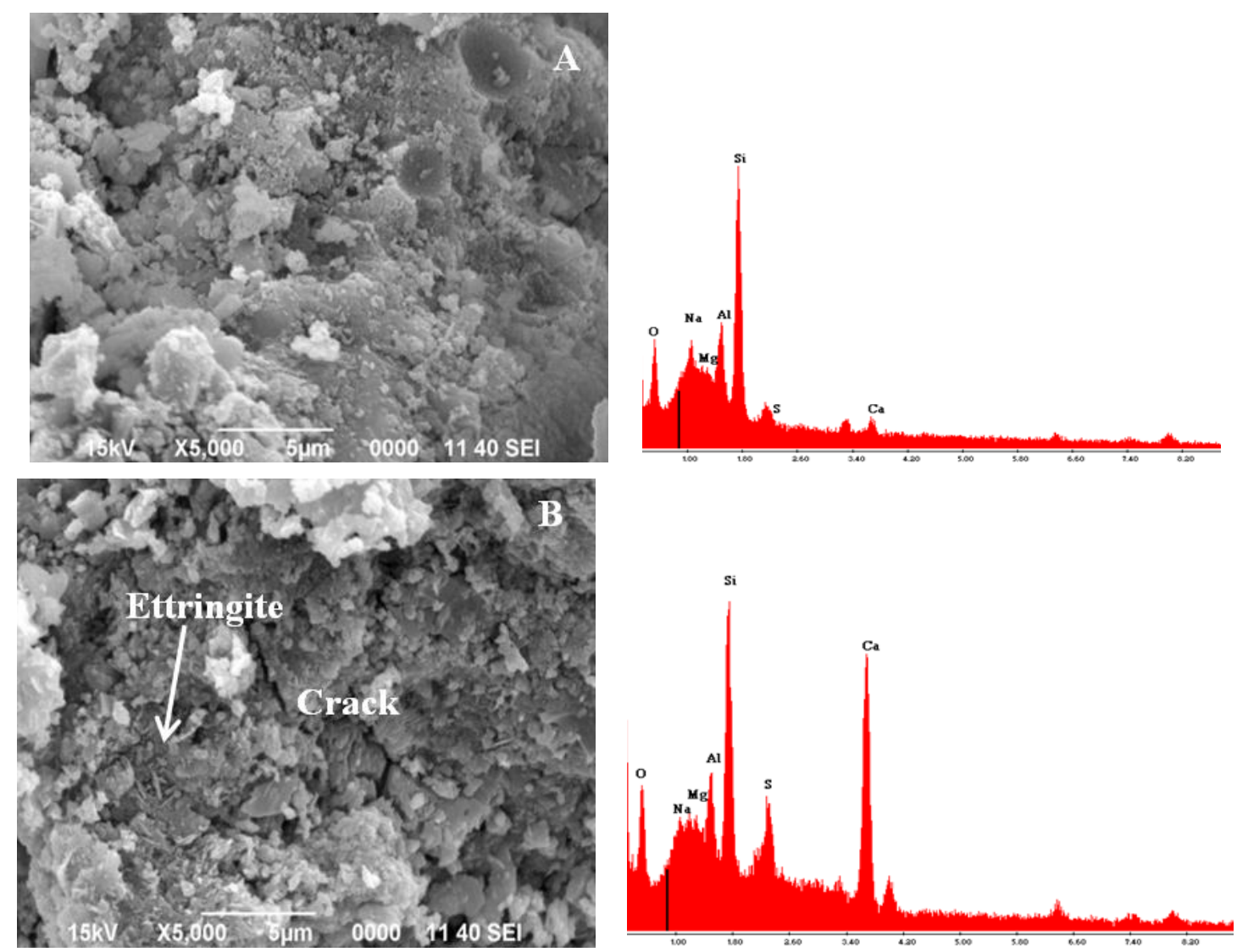

Figure 10. FESEM-EDX of (A) BAG and (B) OPC concretes at the age of 18 months

\subsection{CONCLUSIONS}

The following conclusions are drawn from the present study.

i. The BAG concrete showed better chemical stability after being immersed in $\mathrm{NaCl}$ than OPC concrete.

ii. The N-A-S-H gel systems can have less effect on the structure of a material compared to the Carich gel such as C-S-H like OPC.

iii. The durability performance of both samples can be confirmed by microstructural analysis. The results showed that the structure of BAG concrete has less altered only at certain depth intervals (Disc 1), while the structure of OPC concrete has been altered for the most of the depth interval (Disc 1-3) due to the presence of calcite.

iv. The results of microstructural properties from XRD alone are inadequate. Results from FTIR, TGADTG and FESEM-EDX are essential to support the XRD results.

v. Ettringite does not exist in severely carbonated concrete as proved in both analyses of microstructural characterization.

\section{ACKNOWLEDGEMENTS}

The authors would like to acknowledge UTM for providing the Research University Grant (RUG), VOT No. QJ130000.2522.00H9 and VOT No. QJ130000.2622.11J07 from Ministry of Higher Education (MOHE) of Malaysia for the financial supports. 


\section{REFERENCES}

[1] M. C. G. Juenger, F. Winnefeld, J. L. Provis, and J. H. Ideker, "Advances in alternative cementitious binders," Cement and Concrete Research, vol. 41, no. 12, pp. 1232-1243, Dec. 2011.

[2] J. S. Damtoft, J. Lukasik, D. Herfort, D. Sorrentino, and E. M. Gartner, "Sustainable development and climate change initiatives," Cement and Concrete Research, vol. 38, no. 2, pp. 115-127, Feb. 2008.

[3] E. M. Gartner and D. E. Macphee, "A physico-chemical basis for novel cementitious binders," Cement and Concrete Research, vol. 41, no. 7, pp. 736-749, Jul. 2011.

[4] F. Pacheco-Torgal, J. Castro-Gomes, and S. Jalali, “Alkali-activated binders: A review,” Construction and Building Materials, vol. 22, no. 7, pp. 1305-1314, Jul. 2008

[5] J. Davidovits, "NASTS Award 1994, Journal of Materials Education,” vol. 16, pp. 1-25, 1994.

[6] M. C. G. Juenger, F. Winnefeld, J. L. Provis, and J. H. Ideker, "Advances in alternative cementitious binders," Cement and Concrete Research, vol. 41, no. 12, pp. 1232-1243, Dec. 2011

[7] F. Pruckner and O. E. Gjørv, "Effect of $\mathrm{CaCl} 2$ and $\mathrm{NaCl}$ additions on concrete corrosivity," Cement and Concrete Research vol. 34, pp. 1209$1217,2004$.

[8] M. a. M. Ariffin, M. a. R. Bhutta, M. W. Hussin, M. Mohd Tahir, and N. Aziah, "Sulfuric acid resistance of blended ash geopolymer concrete," Construction and Building Materials, vol. 43, pp. 80-86, Jun. 2013.

[9] C. Shi, a. F. Jiménez, and A. Palomo, "New cements for the 21 st century: The pursuit of an alternative to Portland cement," Cement and Concrete Research, vol. 41, no. 7, pp. 750-763, Jul. 2011.

[10] I. Garcia-Lodeiro, a. Palomo, a. Fernández-Jiménez, and D. E. Macphee, "Compatibility studies between N-A-S-H and C-A-S-H gels. Study in the ternary diagram Na2O-CaO-Al2O3-SiO2-H2O," Cement and Concrete Research, vol. 41, no. 9, pp. 923-931, Sep. 2011.

[11] C. Villa, E. T. Pecina, R. Torres, and L. Gómez, "Geopolymer synthesis using alkaline activation of natural zeolite," Construction and Building Materials, vol. 24, no. 11, pp. 2084-2090, Nov. 2010.

[12] W. K. W. Lee and J. S. J. van Deventer, "Chemical interactions between siliceous aggregates and low-Ca alkali-activated cements," Cement and Concrete Research, vol. 37, no. 6, pp. 844-855, Jun. 2007.

[13] a. Alberti, I. Parodi, G. Cruciani, M. C. Dalconi, and a. Martucci, "Dehydration and rehydration processes in gmelinite: An in situ X-ray singlecrystal study," American Mineralogist, vol. 95, no. 11-12, pp. 1773-1782, Nov. 2010.

[14] "Importance of using the natural pozzolans on concrete durability," vol. 32, no. 42, pp. 1851-1858, 2002.

[15] M. Criado, a. Fernández-Jiménez, a. G. de la Torre, M. a. G. Aranda, and a. Palomo, "An XRD study of the effect of the SiO2/Na2O ratio on the alkali activation of fly ash," Cement and Concrete Research, vol. 37, no. 5, pp. 671-679, May 2007.

[16] P. W. Brown and S. Badger, "The distributions of bound sulfates and chlorides in concrete subjected to mixed $\mathrm{NaCl}, \mathrm{MgSO} 4, \mathrm{Na} 2 \mathrm{SO} 4$ attack," vol. 30, pp. 1535-1542, 2000.

[17] Q. Zhu, L. Jiang, Y. Chen, J. Xu, and L. Mo, "Effect of chloride salt type on chloride binding behavior of concrete," Construction and Building Materials, vol. 37, pp. 512-517, Dec. 2012.

[18] Q. Yuan, C. Shi, G. De Schutter, K. Audenaert, and D. Deng, "Chloride binding of cement-based materials subjected to external chloride environment - A review," Construction and Building Materials, vol. 23, no. 1, pp. 1-13, Jan. 2009.

[19] A. K. Suryavanshi and R. N. Swamy, “CARBONATED CONCRETE STRUCTURAL ELEMENTS,” vol. 26, no. 5, pp. 729-741, 1996.

[20] A. Palomo and A. Ferna, "Mid-infrared spectroscopic studies of alkali-activated fly ash structure," vol. 86, pp. 207-214, 2005.

[21] W. K. W. Lee and J. S. J. van Deventer, "Chemical interactions between siliceous aggregates and low-Ca alkali-activated cements," Cement and Concrete Research, vol. 37, no. 6, pp. 844-855, Jun. 2007.

[22] S. Ahmari, X. Ren, V. Toufigh, and L. Zhang, "Production of geopolymeric binder from blended waste concrete powder and fly ash," Construction and Building Materials, vol. 35, pp. 718-729, Oct. 2012.

[23] I. Ismail, S. a. Bernal, J. L. Provis, S. Hamdan, and J. S. J. Deventer, "Drying-induced changes in the structure of alkali-activated pastes," Journal of Materials Science, vol. 48, no. 9, pp. 3566-3577, Jan. 2013.

[24] M. Frias, S. Goñi, R. García, and R. Vigil de La Villa, "Seawater effect on durability of ternary cements. Synergy of chloride and sulphate ions," Composites Part B: Engineering, vol. 46, pp. 173-178, Mar. 2013. 